\title{
OCUPAÇÃO DAS ENCOSTAS E A FORMAÇÃO DAS ÁREAS DE RISCO A MOVIMENTOS DE MASSA EM BLUMENAU-SC
}

\section{OCCUPATION OF THE SLOPES AND THE GENERATION OF RISK AREAS OF MASS MOVEMENTS IN BLUMENAU CITY-SC}

\author{
Tanice Cristina Kormann1, Luís Eduardo de Souza Robaina² \\ ${ }^{1}$ Universidade Federal do Rio Grande do Sul (UFRGS), Porto Alegre,RS, Brasil \\ ${ }^{2}$ Universidade Federal de Santa Maria (UFSM), Santa Maria,RS, Brasil
}

Correspondência para: Tanice Cristina Kormann (tanice.kormann@gmail.com)

doi: $10.12957 /$ geouerj.2016.16695

Recebido em: 27 nov. 2015 | Aceito em: 6 abr. 2016

\section{SCREENED BY iThenticate}

\section{RESUMO}

A presente pesquisa tem como tema principal a formação das áreas de risco a movimentos de massa no município de Blumenau - SC. Desta forma, a ocupação do espaço urbano é analisada como fator condicionante a formação de áreas de risco com a ocupação de encostas íngremes. Blumenau registra um modelo de ocupação que se forma a partir do avanço sobre áreas de fundo de vale, com lotes paralelos uns aos outros onde cada terreno apresenta uma estreita porção com acesso à drenagem e seu comprimento se estende em direção à montante. Esse processo, que se diferencia das demais áreas de colonização luso-brasileira, resulta numa mancha urbana linear seguindo a rede de drenagem com poucas vias de ligação entre si. Este modelo de ocupação buscava se adaptar à limitação imposta pela topografia, devido à escassez de áreas planas e predomínio dos vales profundos com rios encaixados, indicando forte controle da estrutura geológica. Após a década de 1930 a ocupação avança à encosta, assumindo um caráter mais urbano com a industrialização que se consolidava como principal atividade regional. A limitação imposta pelo meio faz surgir um espaço urbano marcado pela presença de taludes de corte e aterro excessivamente íngremes que induzem a ocorrência de acidentes como ocorridos em 2008 e 2011. A ocupação improvisada das encostas, muitas vezes em áreas irregulares que ultrapassam o perímetro urbano municipal, constitui o maior desafio para o planejamento urbano municipal neste início de século.

Palavras-chave: ocupação urbana; áreas de risco; movimentos de massa; encosta; Blumenau.

\begin{abstract}
This research presents a discussion of the development of risk areas to mass movements in the city of Blumenau - SC. Discusses the urban space occupation process as a conditioning factor the formation of risk areas due to occupation of steep slopes. Blumenau registers a model of occupation that forms from the advance on valley bottom areas, with parallel plots each other where each land has a narrow portion with access to drainage and its length extends toward upstream. This process, which differs from other areas of Luso-Brazilian colonization, resulting in a linear urban area following the drainage network with few lines connecting them. This model of occupation was seeking to adapt to the limitations imposed by topography, due to shortage of flat areas, and predominance of deep valleys with embedded rivers, indicating strong control of the geological structure. After the 1930s the occupation advances to the hillside, assuming a more urban character and the industrialization which was consolidated as the main regional activity. The limitation imposed by means brings about an urban space marked by the presence of excessively steep cut and fill slope that induce the occurrence of accidents such as occurred in 2008 and 2011. The makeshift occupation of hillsides, often in irregular areas beyond the municipal urban area, is the biggest challenge for the municipal urban planning in this new century.
\end{abstract}

Keywords: urban settlement; risk areas; mass movements; slope; Blumenau. 


\section{INTRODUÇÃO}

Desde a formação dos primeiros agrupamentos humanos até a concepção das cidades modernas, a sociedade convive com a ocorrência de eventos de ordem natural que geram perdas sociais e econômicas (VEYRET, 2007). Porém, o aumento da frequência e intensidade da ocorrência de eventos adversos têm se mostrado como tendência nos últimos anos, o que revela a importância de conhecer os fenômenos para minimizar os impactos gerados (TOMINAGA, 2009).

O fenômeno/processo natural abordado neste trabalho é o movimento de massa. Este conceito busca agrupar uma gama de tipologias de eventos associados à mobilização de material na vertente sobre a ação da gravidade (BIGARELLA, 2003). Há uma diversidade de termos diferenciando processos de movimento de massa (também denominado de movimentos gravitacionais), porém, na maioria das vezes, os termos são empregados de maneira coloquial e divergente (a exemplo dos termos desmoronamento, escorregamento e deslizamento). Nesta pesquisa adota-se o conceito de movimento de massa com a finalidade de uma designação genérica do fenômeno que se passa na encosta, sem diferenciação em categorias e tipologias.

A ocorrência de um desastre natural é a materialização do risco, assim definido em função dos danos causados à sociedade, sendo desencadeado por eventos extremos associados a fenômenos/processos naturais. Cabe destacar que apesar dos desastres naturais serem desencadeados por processos da dinâmica natural, eles podem ser induzidos ou intensificados pela ação humana (ROBAINA, 2008). Esta condição coloca a sociedade, ao mesmo tempo como sujeito exposto e agente causador do risco. Deste modo, faz-se importante controlar as formas de apropriação dos espaços naturais e seu processo de ocupação para evitar a formação das áreas de risco.

O Ministério das Cidades (BRASIL, 2004, p. 10) define área de risco como sendo a "área passível de ser atingida por processos naturais e/ou induzidos que causem efeito adverso". Ou seja, a ocupação de áreas naturalmente suscetíveis à ocorrência de processos de dinâmica superficial pode expor a população ao risco de desastres naturais. 
No contexto latino americano a desigualdade social e o crescimento urbano acelerado intensificam o processo de ocupações irregulares muitas vezes situadas nas beiras de rios e nas encostas íngremes (MARICATO, 1996). Deste modo, entende-se que a formação das áreas de risco está intrinsecamente ligada ao processo de formação da cidade, que por sua vez, reflete o fenômeno da urbanização brasileira, caracterizada pela concentração populacional acelerada e patológica.

Sobre as consequências espaciais da urbanização brasileira Maricato (1996, p. 55) ainda considera que “(...) o processo de urbanização com crescimento da desigualdade resultou numa inédita e gigantesca concentração da pobreza". Este tema é abordado conceitualmente pelo Instituto Brasileiro de Geografia e Estatística (IBGE) através do conceito de aglomerado subnormal. O termo visa englobar, para fins de classificação e mapeamento, o conjunto de, ao menos, 51 unidades habitacionais carentes de serviços públicos essenciais, sendo o terreno de propriedade alheia (pública ou particular) com disposição geralmente desordenada e densa (IBGE, 2010b).

Neste contexto, a presente pesquisa pretende contribuir na discussão da formação das áreas de risco a movimentos de massa município de Blumenau-SC. Nas últimas décadas, a temática dos movimentos de massa assume grande relevância para o município de Blumenau.

O Atlas dos Desastres Naturais no Estado de Santa Catarina elaborado por Herrmann (2006) aponta Blumenau como o município catarinense mais atingido por movimentos de massa e inundações através de um inventário das ocorrências registradas entre os anos de 1980 e 2003.

Recentemente ocorreram eventos que causaram sérios danos associados a inundações e movimentos de massa nos anos de 2008 e 2011. No primeiro, houve a decretação de Situação de Emergência e em 2011 foi decretado de Estado de Calamidade Pública. Como resposta, a Prefeitura Municipal organiza, em 2009, um setor de geologia que vem desenvolvendo trabalhos de mapeamento detalhado das áreas de risco no município (XAVIER et al., 2010(a), 2010(b), 2010(c)). 
Na sequência, o trabalho inicia com uma breve caracterização dos principais elementos do meio natural de Blumenau para então apresentar o processo de ocupação do espaço urbano. Estes temas se interconectam como base para a discussão da formação de áreas de risco tendo o enfoque principal a ocupação de encostas íngremes.

\section{A ÁREA DE ESTUDO}

Localizado no médio curso da bacia hidrográfica do Rio Itajaí-Açu e possuindo uma área de pouco mais de $500 \mathrm{~km}^{2}$, o município de Blumenau tem seu território cortado ao meio pelo rio que dá nome à bacia hidrográfica (Figura 1).

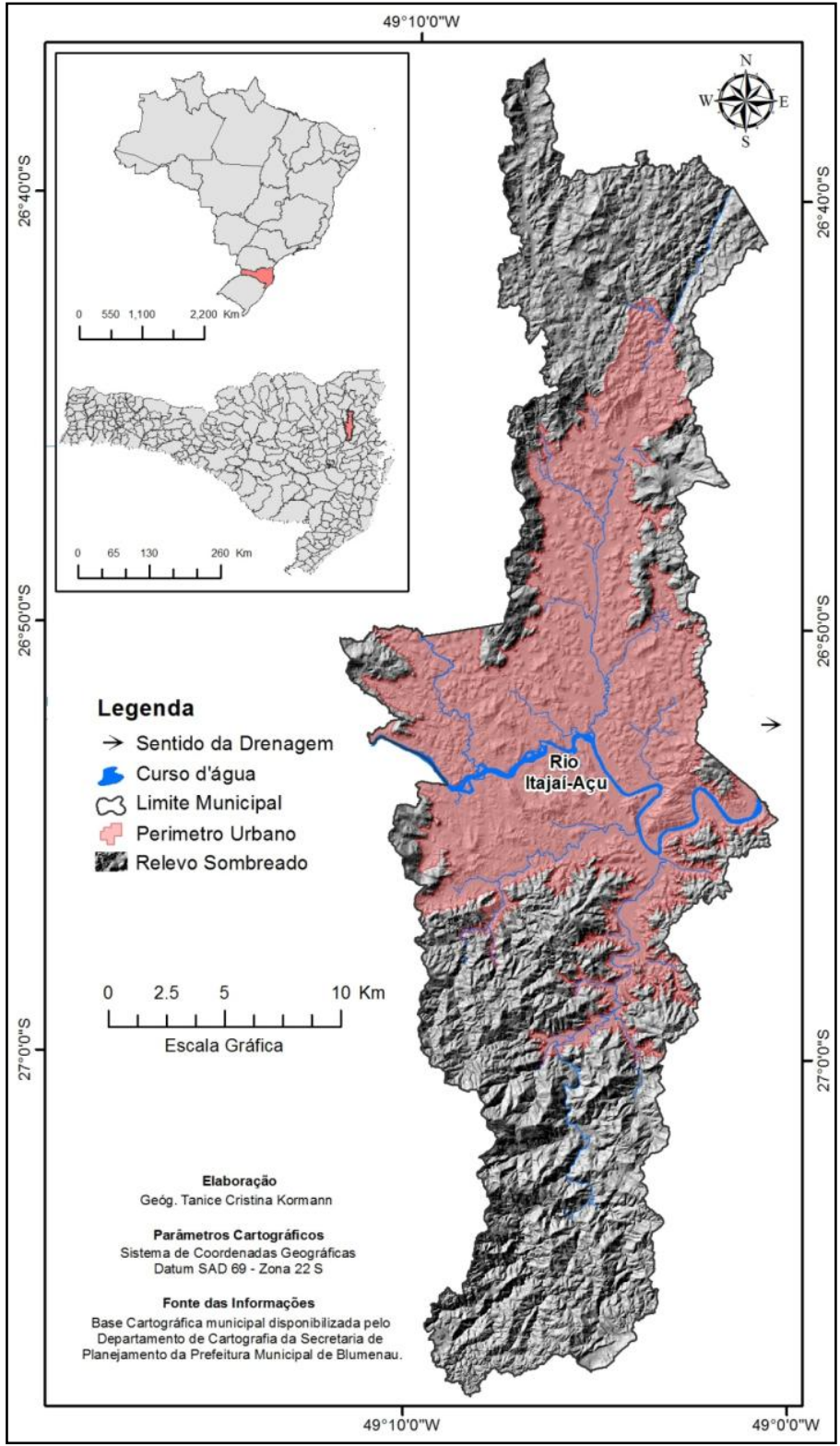


Figura 1. Mapa de localização do município de Blumenau com destaque para a área urbana instalada no entorno das principais drenagens e limitada pelo relevo acentuado.

Os principais divisores de água encontram-se nos limites sul do município, onde o ponto mais alto apresenta uma altitude de $980 \mathrm{~m}$. Nesta porção do território encontra-se a linha de cumeada da Serra do Itajaí, que compõe o conjunto definido por Peluso (1986) como "Região do Litoral e Encostas".

A significativa amplitude altimétrica dá origem a vales profundos com rios encaixados e fortemente condicionados pela estrutura geológica, onde predominam as falhas e fraturas alinhadas na direção nordeste (VIEIRA, 2004). A geologia regional apresenta grande diversidade e complexidade; na porção norte do município a idade avançada das rochas pertencentes ao embasamento cristalino do Complexo Luís Alves sugere a formação de espesso manto de alteração, enquanto na porção sul afloram rochas sedimentares e metamórficas de baixo grau, respectivamente pertencentes ao Grupo Itajaí e Grupo Brusque.

Quanto às características climáticas, o município tem os maiores índices pluviométricos registrados no verão, sendo janeiro o mês mais chuvoso (SANTOS, 1996). O principal sistema responsável pelas chuvas no inverno é o choque entre massas de ar polar e massas de ar quente proveniente de menores latitudes, resultando na frente fria (MONTEIRO; MENDONÇA, 2002). Porém, na primavera e no verão há que se considerar a influência local da umidade proveniente do Oceano Atlântico, já que no leste catarinense as serras atuam como barreira ao ar úmido vindo do oceano, obrigando este a ascender, o que resulta na precipitação. Além destes sistemas atmosféricos, a ocorrência de valores elevados de precipitação também pode resultar da interferência ocasional do El Niño (SANTOS, 1996).

Combinado às condições de suscetibilidade do meio, Blumenau apresenta um processo de ocupação que traz forte influência da rede de drenagem em sua estruturação. A partir das áreas de fundo de vale a ocupação avança até alcançar as encostas. Este fenômeno está atrelado ao modelo colonial de ocupação adotado na maioria das cidades de origem alemã do sul do Brasil. 
A partir da década de 1930, impulsionado pelo crescimento da indústria têxtil regional, o processo de ocupação passa a assumir um caráter mais urbano (SIEBERT, 1999). A concentração populacional estimulada pelo o crescimento econômico faz com que o município atingisse, na década de 1980, o terceiro maior contingente populacional do estado de Santa Catarina. Atualmente, o último Censo indica uma população de 307.378 habitantes (IBGE, 2010a). Diante deste cenário, os últimos dados censitários apontam, ainda, Blumenau como o município catarinense com maior número de habitantes vivendo em aglomerados subnormais (IBGE, 2010b).

\section{PROCEDIMENTOS METODOLÓGICOS}

A constatação de que ações antrópicas tem resultado em interferências no meio conduzem ao surgimento de novas perspectivas de análise que buscam identificar os reflexos dessas transformações no espaço e no tempo. Indo ao encontro desta perspectiva Vitte (2008) reforça esta colocação ao apontar a necessidade de pensar no processo de formação da cidade como elemento de análise em estudos tratando de problemáticas ambientais que nela ocorrem.

Especificamente a respeito de estudos relativos à temática dos riscos Mendonça (2011) chama a atenção para a importância de considerar elementos socioeconômicos, culturais e políticos para 0 estudo dos riscos em ambientes urbanos. A análise de elementos da dinâmica social que interagem com o fenômeno/processo do meio físico contribui ao reforçar o caráter aplicado do conhecimento, tornando possível auxiliar nas etapas de diagnóstico, prognóstico e recuperação de encostas onde ocorrem processos de movimentos de massa (GUERRA; MARÇAL, 2010).

De forma geral, os procedimentos operacionais tiveram início com o levantamento bibliográfico, que abordou temas como: processo de ocupação e o sistema colonial de distribuição de terras; a industrialização e a fragmentação da propriedade rural; a urbanização e a formação das áreas de risco nas encostas. 
Os trabalhos de Hering (1987) e Seyferth (1999) contribuem ao caracterizar a forma de distribuição dos lotes durante o período colonial. O processo de urbanização é alcançado com a tese de Siebert (1999) e especificamente tratando das áreas de risco temos o estudo de caso de Vieira (2004) a respeito da Sub-Bacia do Ribeirão Araranguá onde consta a formação das primeiras áreas de risco do município, porém com enfoque local.

Após a etapa de levantamento bibliográfico tem-se o levantamento de dados estatísticos e dados primários. Os dados estatísticos foram obtidos junto ao sítio do IBGE e os dados primários envolvendo cartografia colonial foram encontrados no referencial bibliográfico citado anteriormente enquanto a cartografia atual foi cedida pelo setor de cartografia da Prefeitura Municipal de Blumenau.

Nesse órgão foram obtidas informações referentes aos seguintes temas: rede de drenagem; limite dos bairros; arruamentos; informações de altimetria na escala de 1:2.000 (curvas de nível com intervalo de $5 \mathrm{~m}$ ); além de um mosaico de imagens de satélite de alta resolução espacial do sensor QuickBird ${ }^{\circledR}$ cujo imageamento ocorreu no final de 2008 e início de 2009, com resolução espacial de 60 $\mathrm{cm}$.

A Prefeitura Municipal de Blumenau informou ainda que as informações da rede de drenagem foram elaboradas a partir de dados obtidos em campo e complementadas por edição vetorial a partir da imagem de satélite, o que resultou na descontinuidade e inexistência desta informação em algumas porções do território municipal.

Os dados foram organizados de forma a permitir a construção e organização de um banco de dados em ambiente SIG. A combinação de informações foi realizada no software Arc Gis 10® permitindo a elaboração dos mapas apresentados na sequência.

Os trabalhos de campo permitiram avaliar situações levantadas durante a análise dos produtos cartográficos. Assim, foram descritas diferentes situações com apoio de fotografias georreferenciadas que complementam os dados cartográficos em algumas das ilustrações ao longo do trabalho. 


\section{O PROCESSO DE OCUPAÇÃO E URBANIZAÇÃO DE BLUMENAU}

O território de Santa Catarina tem seu povoamento iniciado no século XVII com a política portuguesa "uti possi de tis". Sob este modelo de ocupação são fundados povoados litorâneos que permitiram assegurar a posse e definir os limites da colônia ultramarinha de Portugal (PIAZZA, 1982).

No século XIX a definição das fronteiras de Santa Catarina reforça a necessidade de interligar o litoral ao planalto. Neste cenário, o governo passa a estimular o desenvolvimento da colonização utilizando os vales dos principais rios como "vias de penetração" do território (HERING, 1987; SEYFERTH, 1999).

Desta forma, tem início em 1850 o processo de ocupação de Blumenau. Um grupo de imigrantes alemães liderados por Hermann Bruno Otto Blumenau viaja pelo Rio Itajaí-Açu, percorrendo seu curso até a porção do médio vale, onde se estabelecem e fundam a Colônia Blumenau.

À medida que ocorria o estabelecimento das colônias, estas se tornavam base para a expansão da ocupação rumo ao interior. A concentração espacial das colônias e a homogeneidade étnica dos imigrantes (predominantemente alemães e italianos) se combinam na formação de sociedades que destoavam dos núcleos de origem portuguesa, produzindo um modelo de ocupação do território diferenciado (PELUSO, 1991; SEYFERTH, 1999).

Peluso (1991) enfatiza a importância dos aspectos culturais como elemento chave para a compreensão do modo de organização desses povoados. Seyferth (1999) complementa esta discussão, ao considerar que a origem de tal diferenciação pode estar na forma como eram distribuídos os lotes na Alemanha antes da vinda dos imigrantes. A autora compara a forma de ocupação da colonização àquela existente na Alemanha na época da migração:

Outra característica peculiar a esse povoamento é a forma que tomou a distribuição de terras entre os colonos, semelhante à colonização da região montanhosa do leste da Alemanha no final da Idade Média: o tipo de povoamento chamado de Waldhufen (SEYFERTH, 1999, p. 47). 
Waldhufen se refere ao tipo de povoamento característico do período medieval das regiões alemãs da Floresta Negra, Odenwald, leste da Mittelgebirge e em partes das terras baixas do norte da Alemanha (SEYFERTH, 1999). O termo pode ser decomposto para melhor compreensão; sendo "Wald" correspondente a "floresta" enquanto "Hufen" se refere à área que cada camponês recebia para cultivo, ou seja, a unidade produtiva.

Desta forma, um grupo culturalmente homogêneo, e sob condições ambientais relativamente similares (especialmente no que se refere ao relevo acidentado formando vales estreitos), reproduz uma organização espacial semelhante a existente no leste da Alemanha. Nas palavras de Peluso (1991, p. 356): “(...) são as condições geográficas do sítio e a cultura do grupo que criou a cidade que orientam o arranjo do espaço urbano". Para este autor, a organização espacial da Colônia Blumenau reflete ainda o princípio da racionalidade, sendo esta uma das principais características dos planos urbanos de cidades alemãs.

Com um sistema fragmentado em fileiras de lotes posicionados perpendicularmente à drenagem e paralelos entre si tem-se a formação de uma espécie de múltiplas sedes situadas nas áreas de confluência de drenagem e/ou desta com os caminhos. Tal condição é resultado da ausência de um local que exerça forte centralidade neste modelo de ocupação.

A dispersão espacial deste modelo é reflexo da organização a partir de linhas de colonização que, por determinação do meio físico, ocorre ao longo do vale, fazendo com que, espacialmente, o povoado assumisse forma alongada, com os caminhos surgindo paralelos aos cursos d'água. Os lotes foram definidos paralelamente uns aos outros, seguindo a drenagem e se estendendo numa longa faixa em direção ao fundo do vale (SIEBERT, 1999).

Desta maneira, todos os lotes abrangiam uma faixa que se estendia da planície até a encosta, com largura de 200 a 300 metros com 1000 metros ou mais de comprimento, fazendo com que cada proprietário possuísse uma parte da qual pudesse fazer uso agrícola e o restante do terreno geralmente 
se tratava de encostas íngremes, que permanecem como reservas florestais durante o período colonial (HERING, 1987).

Esta distribuição garantia a instalação da moradia na parte menos inclinada do lote e próximo aos cursos d'água, destinando o restante da área cultivável do terreno para a agricultura de subsistência. Outra importante característica do modelo colonial germânico é que o povoamento ao se instalar buscava se adaptar ao relevo, evitando a utilização de áreas de relevo íngreme para tal finalidade.

Os povoados são instalados nas áreas mais planas de fundo de vale, deixando como reserva florestal as encostas mais inclinadas. Deste modo, os principais rios e ribeirões determinam o traçado dos lotes e, consequentemente, toda a ocupação posterior ao período colonial a partir do qual ocorre a formação da malha urbana. Para ilustrar esse processo de ocupação através dos fundos de vale a Figura 2 apresenta uma sobreposição da rede de drenagem e área urbana atual com os lotes coloniais distribuídos em 1864 e 1872. 


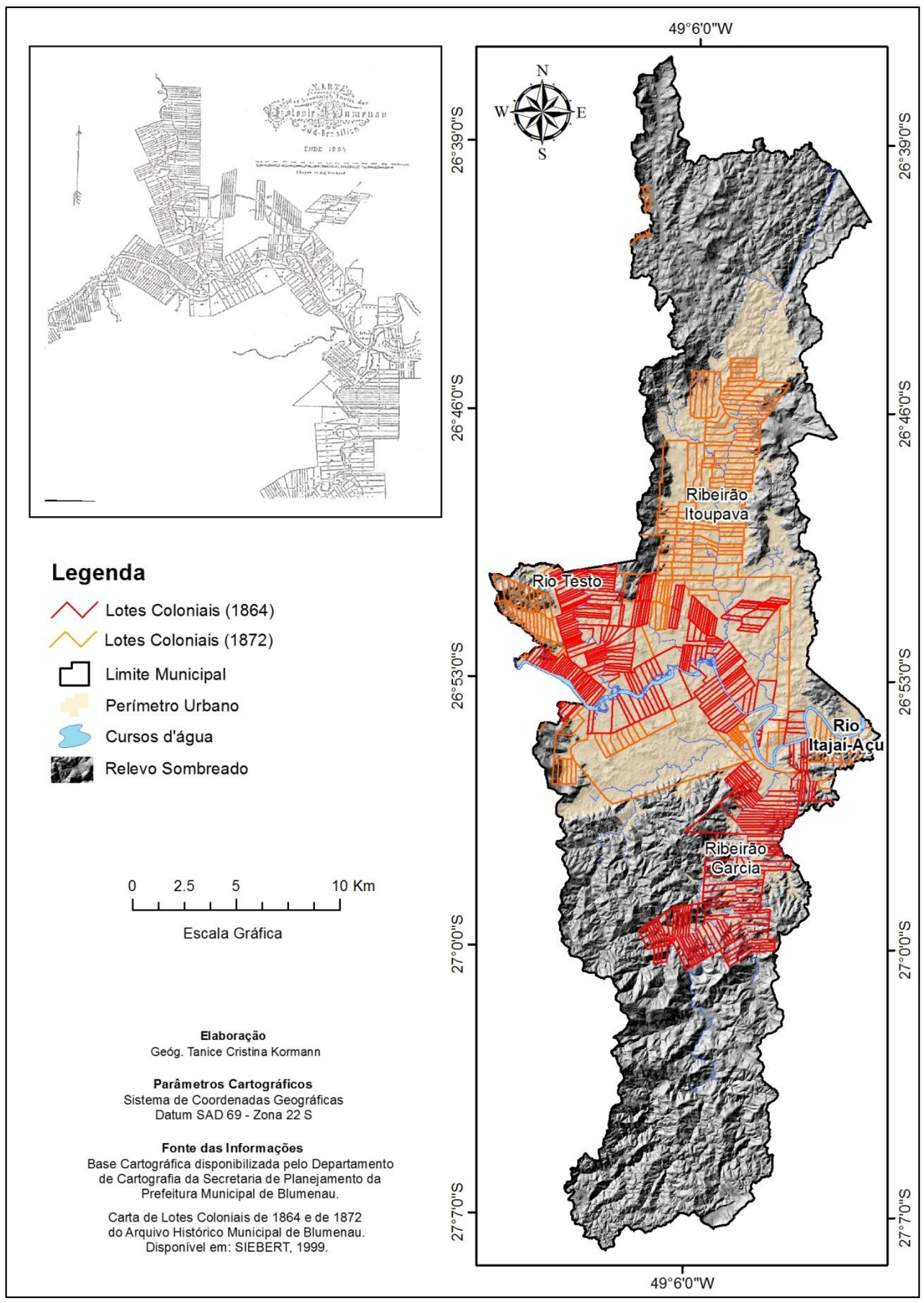

Figura 2. A figura a presenta uma sobreposição dos lotes da Colônia Blumenau nos anos de 1864 e 1872 à atual área urbana e a rede de drenagem. 
Os lotes distribuídos em 1864 haviam promovido o avanço da ocupação da Colônia Blumenau; na direção oeste subindo o Rio Itajaí-Açu, na direção sul ao longo do Ribeirão Garcia, além dos Vales do Ribeirão Itoupava, do Rio Testo e do Rio dos Cedros. Interessante destacar que grande parte do que atualmente constitui a área urbana de Blumenau já havia sido distribuída como lotes aos imigrantes em 1864 (SIEBERT, 1999).

A Carta de Lotes Coloniais de 1872 retrata uma expansão principalmente na direção dos tributários a oeste da sede, o que ultrapassa o atual limite municipal de Blumenau através do avanço pelo Ribeirão Warnow na margem direita e pelo Ribeirão Benedito e Cedro na margem esquerda do Rio Itajaí-Açu.

O incremento populacional impulsiona a existência das primeiras fábricas. Na virada do século XIX para o XX a economia do Vale do Itajaí começa a apresentar condições para uma mudança na estrutura produtiva. Ao cessar a instalação de novas colônias pela indisponibilidade de terras a oeste, as localidades mais desenvolvidas conquistam independência político administrativa no primeiro grande ciclo de emancipações do Vale do Itajaí.

Neste contexto, o término do processo de colonização e a fragmentação do território político e administrativo na década de 1930 culminam na urbanização de Blumenau. O lote colonial passa a sofrer fragmentação, e ao sofrer loteamento é que a ocupação atinge as encostas com maiores inclinações, formando taludes mais inclinados.

\section{A FRAGMENTAÇÃO DA PROPRIEDADE RURAL E A INDUSTRIALIZAÇÃO}

A maioria dos imigrantes europeus trouxe algum conhecimento técnico a julgar por suas diferentes especialidades laborais. As habilidades trazidas pelo imigrante auxiliam na formação das primeiras fábricas a partir do aprimoramento das técnicas artesanais. Assim, a experiência do imigrante com o artesanato e, principalmente no caso do imigrante tardio, o contato com o início da revolução industrial na Alemanha são determinantes para o desenvolvimento industrial do Vale do Itajaí (HERING, 1987). 
Este processo ocorre especialmente no ramo têxtil, onde as primeiras iniciativas surgem muito cedo, praticamente como uma evolução do processo produtivo de artigos que visavam atender as necessidades do mercado local, já que produtos acabados eram fortemente taxados. Na virada do século ocorre a inserção da indústria têxtil no mercado regional e nacional.

Neste momento, a expansão das fábricas resulta na inversão da economia; gradativamente o setor agrícola perde importância enquanto ganha impulso o setor industrial. Como consequência, a propriedade rural no município de Blumenau passa a sofrer atomização. Ocorre então, a transformação funcional do lote agrícola; o espaço rural passa a se tornar urbano.

As indústrias que antes estavam dispersas nas linhas coloniais passam a ser englobadas pela urbanização. Assim, a indústria têxtil contribui para alterar o padrão de ocupação através da instalação de residências de operários nas proximidades da fábrica, configurando uma malha urbana em que espaços de moradia e áreas industriais se mesclam e os lotes que no período colonial apresentavam um baixo adensamento das moradias, especialmente, em direção à encosta, passam por um adensamento significativo e avanço das ocupações para as áreas mais íngremes do lote (Figura 3).

Sobre o assunto, Butzke (1995, p. 151) complementa:

A medida em que a população crescia e demandava mais espaços para ocupar, os antigos lotes coloniais (Hufen) tomando as áreas deixadas entre os vales inicialmente ocupados. Como este processo não se fez acompanhado de planejamento adequado, hoje grandes distorções podem ser observadas, seja em termos da estrutura viária, seja na localização das construções em locais inadequados.

Dessa forma, além da influência do meio, a malha urbana de Blumenau foi condicionada também pela estrutura fundiária do período colonial que segue marcando o espaço urbano até os dias de hoje (SIEBERT, 1999). 


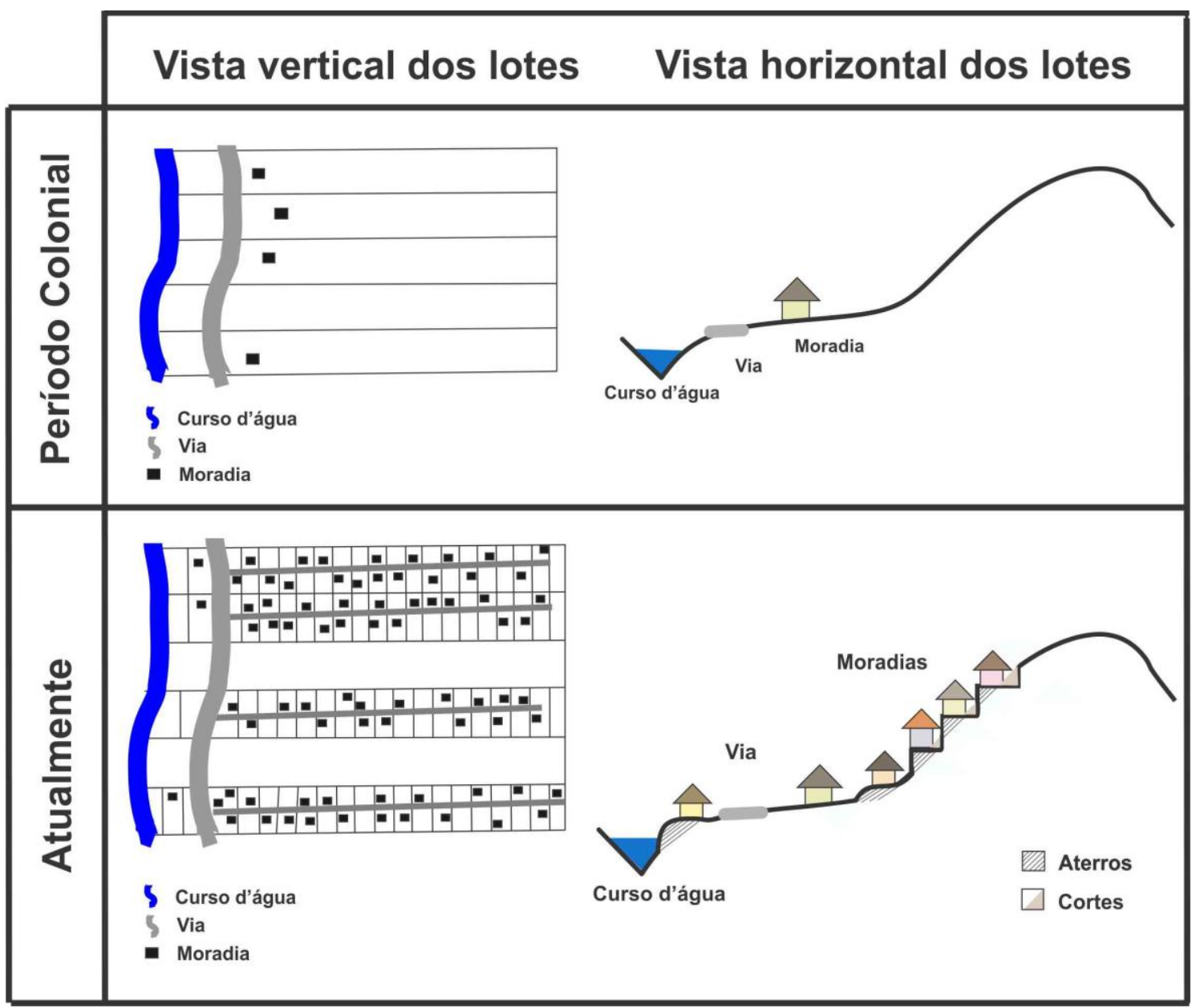

Figura 3. Modelo ilustrativo da fragmentação dos lotes; no quadro superior a distribuição dos lotes no período colonial e no quadro inferior o fracionamento do lote resultante do processo de urbanização.

Fonte: Adaptado de SIEBERT (1999).

A Figura 4 registra esta influência através de uma fotocarta sobrepondo os limites dos antigos lotes coloniais, a rede de drenagem, as curvas de nível e o perímetro urbano à imagem de satélite de alta resolução espacial. No canto superior direito da fotocarta está localizada a fotografia da área, que exemplifica o processo de ocupação avançando a partir do fundo de vale, onde está instalada a via. A partir dela as moradias se instalam encosta acima, indicando uma ocupação que altera a inclinação original do talude através de cortes e aterros. 


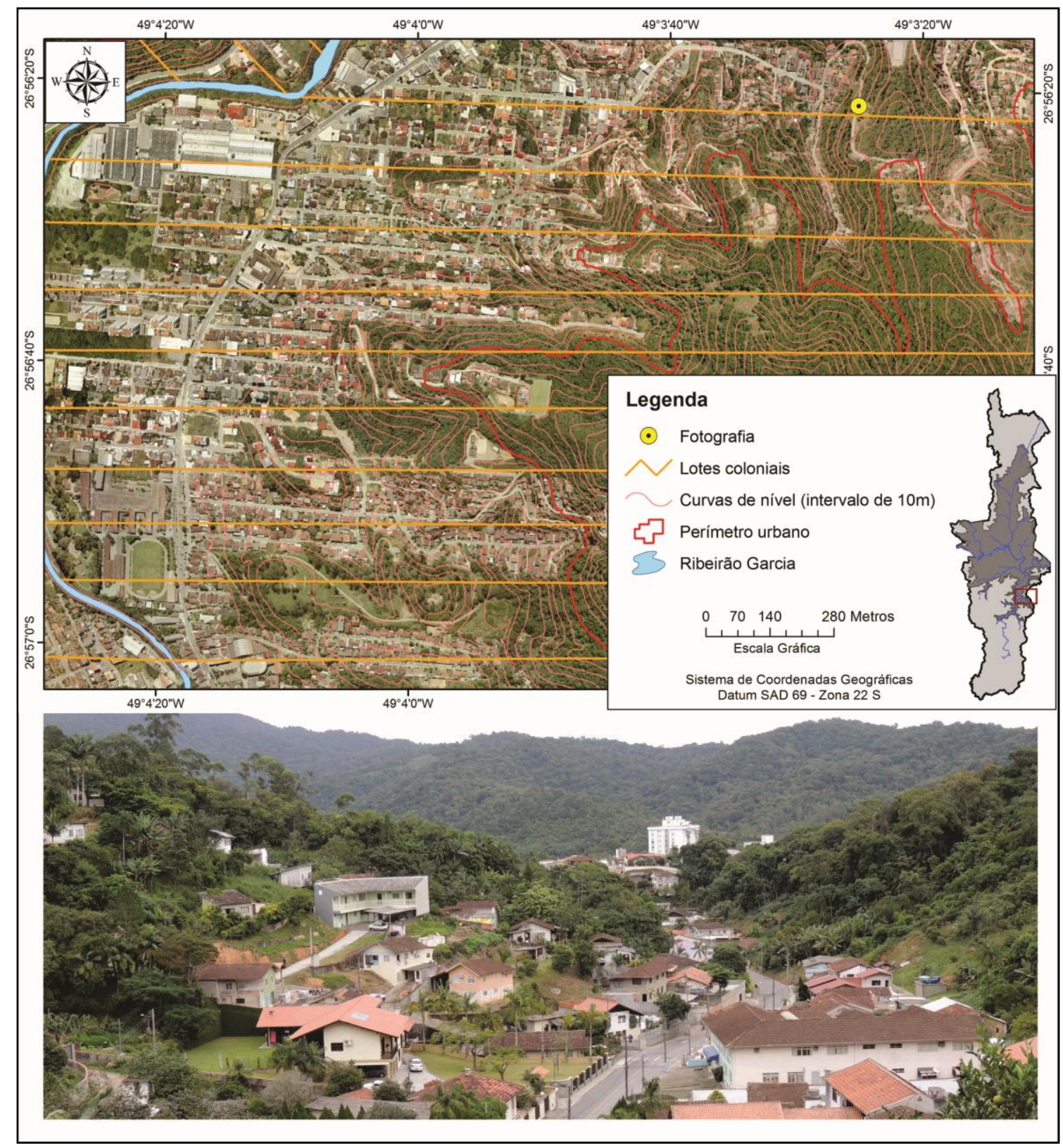

Figura 4. Influência dos lotes coloniais na malha urbana atual. A fotografia tirada para a direção oeste ilustra 0 avanço da ocupação a partir do fundo de vale até alcançar a encosta, através de uma sequência de cortes e aterros.

A divisão dos lotes coloniais ocorria geralmente a partir das heranças, através das gerações. De acordo com Siebert (1999) a ocupação avança a encosta seguindo a antiga estrutura linear do lote colonial, o que ocorre de modo mais significativo a partir da década de 1950. Neste processo a intervenção no relevo torna-se comum, como ilustrado na Figura 4. 
Assim surge uma ocupação escalonada através de uma sequência de cortes e aterros muito comum em áreas com o predomínio de encostas íngremes e vales em "V", como em algumas porções do município de Blumenau. A sobreposição de ocupações encosta acima sem um planejamento na intervenção como um todo torna a situação ainda mais complexa. Este processo é um dos principais motivos para a instabilização de encostas e o surgimento de áreas de risco.

\section{O SURGIMENTO DE ÁREAS DE RISCO ASSOCIADAS À DINÂMICA DE ENCOSTA}

Os primeiros registros de ocupações irregulares situadas em encostas e sujeitas à ocorrência de movimentos de massa no município de Blumenau são da década de 1930. Localizado no Morro da Caixa D’água, próximo ao centro de Blumenau, constitui-se o primeiro aglomerado subnormal de Blumenau.

A situação permaneceu até o ano de 1950, quando o centenário da cidade mobiliza uma força tarefa com o objetivo de retirar os moradores de morros mais próximos ao centro em função de questões estéticas e paisagísticas (VIEIRA, 2004). Apesar da transferência, esta população permanece ocupando áreas sem o título de propriedade e em situação de suscetibilidade frente ao risco de processos da dinâmica superficial.

A Figura 5 apresenta um mapa ilustrando a origem e o destino da população transferida da Favela Farroupilha. Este mapa apresenta uma sobreposição da malha urbana atual e dos limites dos aglomerados subnormais fornecidos pelo IBGE (2010b), o que permite inferir que as áreas de destino dos moradores da antiga Favela Farroupilha constituem hoje alguns dos atuais aglomerados subnormais do município de Blumenau. Na prática, ocorre a transferência do problema para outro local.

Nas décadas de 1960 e 1970 são registrados os maiores índices de crescimento demográfico, o que coincide com o aumento no número de empregados na indústria. Como reflexo, nas décadas de 1970 e 1980 ocorre a ocupação da maioria das áreas periféricas ao centro que hoje correspondem a núcleos de 
habitações subnormais. Neste contexto, surgem novas áreas de ocupação irregular, a exemplo do Morro da Pedreira, no bairro Ponta Aguda, e da Rua Pedro Kraus Senior, no bairro Vorstadt (SIEBERT, 1999).

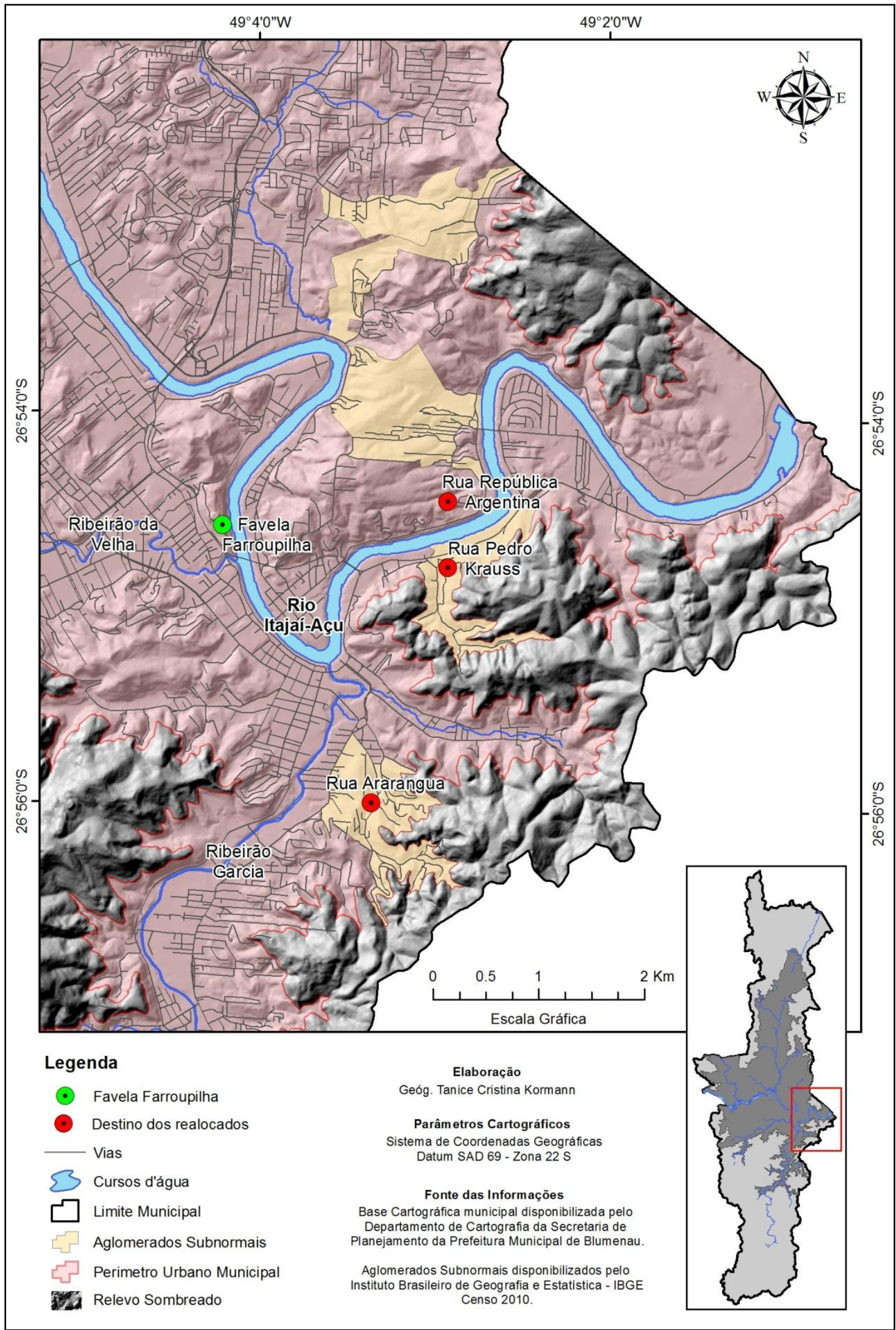


Figura 5. Mapa indicando a localização das áreas de risco que surgem a partir da extinção da Favela Farroupilha, o que coincide com os aglomerados subnormais delimitados pelo IBGE.

Com isso, têm-se as primeiras medidas visando direcionar a ocupação para a porção norte do município. Nas décadas de 1980 e principalmente 1990 tem-se a intensificação da ocupação da parte norte do território blumenauense, o que é confirmado pela ampliação do perímetro urbano na porção norte e redução do perímetro urbano ao sul realizada através do Plano Diretor de 1996. Porém, esta medida não assegura a diminuição da problemática.

Novos aglomerados subnormais surgem em áreas mais afastadas do centro urbano, especialmente na porção norte de Blumenau, área inserida no perímetro urbano na década de 1990. Esta situação revela que, mesmo a ocupação mais recente apresenta problemas quanto ao avanço da das moradias em direção à encosta.

O fato de o perímetro urbano ter "encolhido" não significa que as áreas de encostas deixaram de ser ocupadas. O que ocorre é que parte das áreas inadequadas à ocupação não estão mais abrangidas pelo perímetro urbano municipal. A Figura 6 ilustra esta situação a partir da sobreposição da imagem de satélite ao perímetro urbano e à rede de drenagem, fato que ilustra uma situação comum na porção sul do território municipal (região onde o perímetro urbano foi reduzido). 


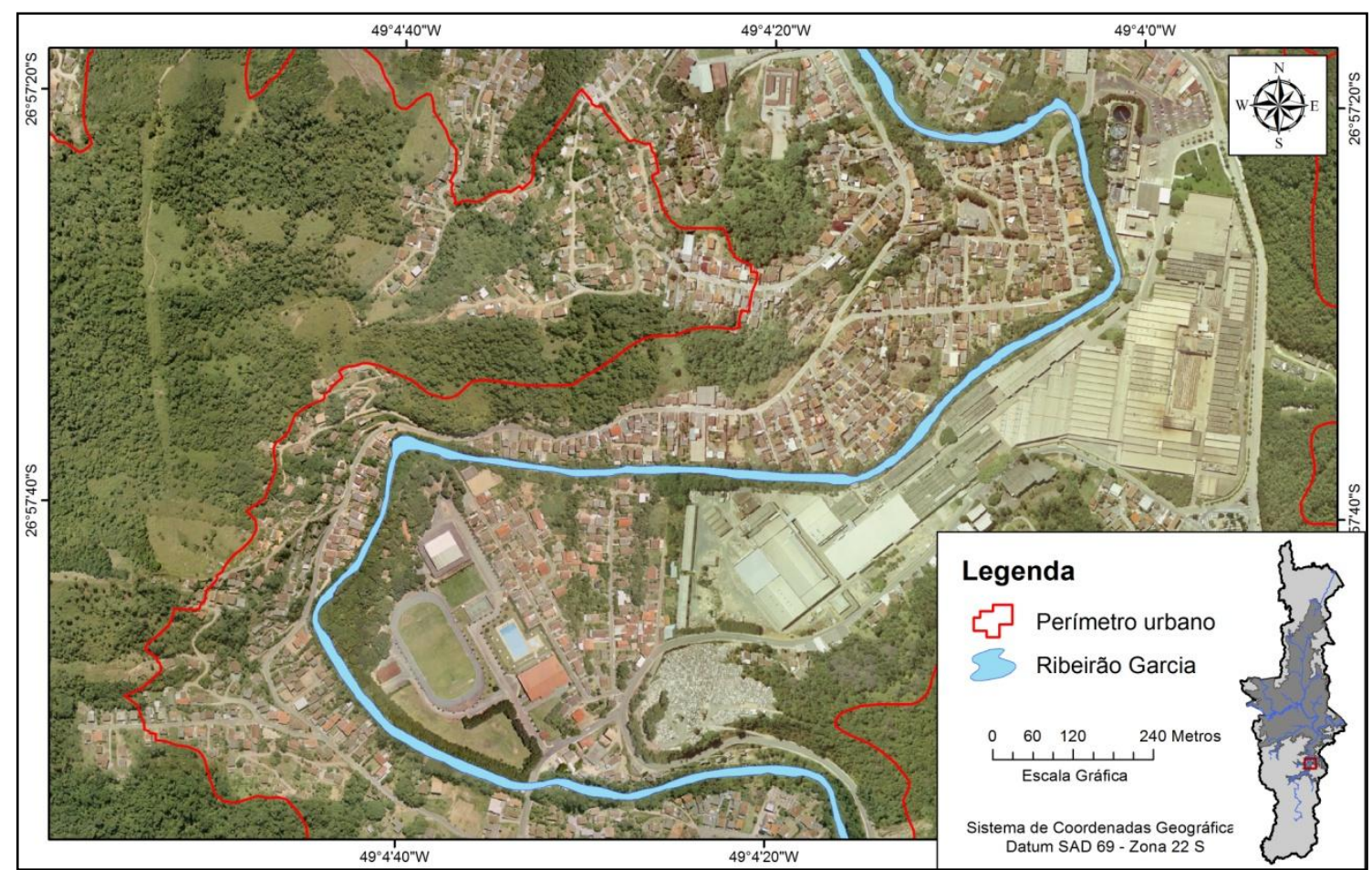

Figura 6. Ilustração da ocupação urbana que ultrapassa o perímetro urbano municipal.

Os dados do último Censo realizado pelo IBGE em 2010 indicam a dimensão da problemática nos dias de hoje. São 23.131 pessoas ocupando domicílios em 17 áreas classificadas como aglomerados subnormais em Blumenau (IBGE, 2010b).

O resultado se torna mais expressivo se considerarmos a população total do município (307.378 habitantes). 0 percentual da população em aglomerados subnormais é de 7,5\%. Apesar de ser a terceira cidade mais populosa do estado, Blumenau supera Joinville e Florianópolis, constituindo-se no município catarinense em que mais pessoas vivem em habitações subnormais.

Estas condições fazem surgir uma ocupação improvisada e muitas vezes irregular, desafiando o planejamento urbano ao intensificar o aspecto tentacular que assume a mancha urbana de Blumenau. Formam-se nichos de ocupação urbana adentrando o relevo acidentado, muitas vezes escondidos em meio à densa vegetação ou ao estreito vale fluvial.

\section{CONSIDERAÇÕES FINAIS}


Assim como a maioria das grandes cidades brasileiras, Blumenau apresenta marcas de um processo de urbanização acelerado e que foge ao controle das medidas de regulação do espaço urbano. Apesar do cenário comum, a influência do processo de ocupação adotado no período colonial está registrada na configuração atual do espaço urbano que avança a encosta a partir dos fundos de vale.

Blumenau é ocupada através da distribuição de lotes coloniais que privilegiam as planícies fluviais. A significativa amplitude e os vales profundos com rios encaixados e fortemente condicionados pela estrutura geológica contribuem para uma acentuada suscetibilidade do meio a ocorrência de movimentos de massa.

Sob estas condições a ocupação alcança a encosta por volta da década de 1930, fato que coincide com o processo de fragmentação dos lotes coloniais. Deste modo, além da influência do meio, a malha urbana de Blumenau foi condicionada também pela estrutura fundiária do período colonial, o que deu origem a uma ocupação escalonada através de uma sequência de cortes e aterros em áreas de encostas íngremes sem o devido planejamento das intervenções.

Os dados do último censo indicam que 23.131 pessoas residem em habitações subnormais, o que permite dimensionar a problemática. A ocupação improvisada das encostas, muitas vezes em áreas irregulares que ultrapassam o perímetro urbano municipal, constitui o maior desafio para o planejamento urbano municipal neste início de século.

\section{AGRADECIMENTOS}

Os autores agradecem à Diretoria de Cartografia da Prefeitura Municipal de Blumenau e ao apoio do POSGEA-UFRGS através de recursos financeiros da CAPES que permitiram o desenvolvimento desta pesquisa, parte integrante da dissertação de mestrado intitulada: "Ocupação de encostas no município de Blumenau - SC: estudo da formação das áreas de risco a movimentos de massa”.

\section{REFERÊNCIAS}


BIGARELLA, J. J. et al. Estrutura e origem das paisagens tropicais e subtropicais. Florianópolis: Ed. da UFSC, v. 3, 2003.

BRASIL. MINISTÉRIO DAS CIDADES/INSTITUTO DE PESQUISAS TECNOLÓGICAS. Treinamento de téenicos municipais para o mapeamento e gerenciamento de áreas urbanas com risco de escorregamentos, enchentes e inundações. Apostila de treinamento. 2004. 73p.

BUTZKE, I. C. Ocupação de áreas inundáveis em Blumenau/SC. 1995. 246 f. Dissertação (Mestrado em Geografia) Universidade Estadual Paulista, Rio Claro: São Paulo, 1995.

GUERRA, A. J. T.; MARÇAL, M. dos S. Geomorfologia Ambiental. 3. ed. Rio de Janeiro: Bertrand Brasil, 2010, 190p.

HERING, M. L. R. Colonização e indústria no Vale do Itajaí: o modelo catarinense de desenvolvimento. Blumenau: Ed. da FURB, 1987, 328 p.

HERRmann, M. L. de P. (org.) Atlas de desastres naturais do estado de Santa Catarina. Secretaria de Estado de Segurança Pública e Defesa do Cidadão. Florianópolis, 2006. Disponível em: < http://www.ceped.ufsc.br/wpcontent/uploads/2006/01/Atlas_Ceped.pdf > Acesso em: 20 fev. 2011.

INSTITUTO BRASILEIRO DE GEOGRAFIA E ESTATÍSTICA. Censo 2010a: resultados divulgados no Diário Oficial da União $\quad$ em $\quad 04.11 .2010 . \quad$ Disponível em: < http://www.ibge.gov.br/home/estatistica/populacao/censo2010/resultados_dou/SC2010.pdf > Acesso em: 08 out. 2011.

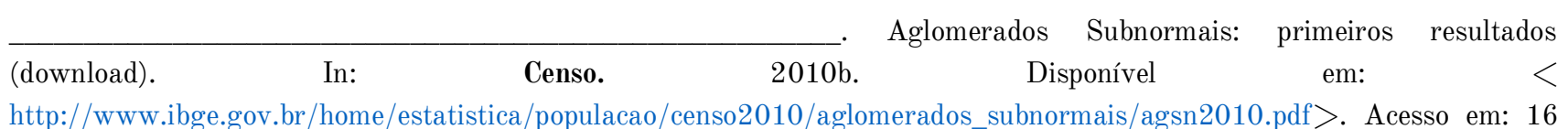
nov. 2013.

MARICATO, E. Metrópole na periferia do capitalismo: ilegalidade, desigualdade e violência. São Paulo: HUCITEC, 1996. $141 \mathrm{p.}$

MONTEIRO, M. A.; MENDONÇA, M. Dinâmica atmosférica no estado de Santa Catarina. In: HERRMANN, M. L. de P. (org.) Atlas de desastres naturais do estado de Santa Catarina. Secretaria de Estado de Segurança Pública e Defesa do Cidadão. Florianópolis, 2006. Disponível em: < http://www.cfh.ufsc.br/ gedn/atlas/Atlas_Ceped.pdf $>$ Acesso em: 20 fev. 2011. p. $5-10$.

PELUSO JR, V. A. O relevo do território catarinense. Geosul. v. 2, p. 7-78, 1986.

PELUSO JR, V. A. Tradição e plano urbano. In: Estudos de geografia urbana de Santa Catarina. Florianópolis: Ed. da UFSC, 1991, 396 p. (publicado originalmente no Boletim da Comissão Catarinense de Folclore. Ano V, n. 15/16, 1953).

PIAZZA, W. F. A colonização de Santa Catarina: obra premiada pelo BRDE no concurso regional de histórica. Porto Alegre: BRDE, 1982, 311 p.

ROBAINA, L. E. de S. Espaço urbano: relação com os acidentes naturais no Brasil. Ciência e Natura. Santa Maria, v. 5, n. 2 ; dez. 2008. p. $93-105$.

SANTOS, G. F. dos. Vale do Garcia (Blumenau - SC): análise climato-geomorfológica e a repercussão dos episódios pluviais no espaço urbano. São Paulo, 1996. Tese de Doutorado em Geografia. Universidade de São Paulo, 1996. 362 p. 
SEYFERTH, G. A colonização alemã no Vale do Itajaí-Mirim: um estudo econômico. 2. ed. Porto Alegre: Ed. Movimento, 1999, 159 p.

SIEBERT, C. F. A evolução urbana de Blumenau: o (des)controle urbanístico e a exclusão sócio-espacial. 1999.190 f. Dissertação (Mestrado em Geografia) - Universidade Federal de Santa Catarina, Florianópolis, 1999.

TOMinAGA, L. K. Desastres naturais: por que ocorrem? In: TOMINAGA, L. K.; SANTORO, J.; AMARAL, R. (Org.). Desastres naturais: conhecer para prevenir. São Paulo: Instituto Geológico, 2009. cap 1, p. 11-24.

VIEIRA, R. Um olhar sobre a paisagem e o lugar como expressão do comportamento frente ao risco de deslizamento. 2004. Tese de Doutorado (Doutorado em Geografia). Florianópolis: Universidade Federal de Santa Catarina, 2004.

VEYRET, Y. (org.) Os riscos: o homem como agressor e vítima do meio ambiente. São Paulo: Contexto, 2007.

VITTE, A. C. Posfácio. In: NUNES, J. O. R.; ROCHA, P. C. (Org.) Geomorfologia: aplicação e metodologias. São Paulo: Expressão Popular, 2008.

XAVIER, F. F., et al. Caracterização dos acidentes geológicos e carta de uso recomendado do solo da região da rua Pedro Krauss Sênior, Blumenau/SC. In: SIMPOSIO BRASILEIRO DE CARTOGRAFIA GEOTECNICA E GEOAMBIENTAL, 7., 2010, Maringá. Anais...Maringá: Universidade Estadual de Maringá, 2010(a).

- Caracterização dos acidentes geológicos e carta de uso recomendado do solo da sub-bacia do ribeirão Araranguá. In: SIMPOSIO BRASILEIRO DE CARTOGRAFIA GEOTECNICA E GEOAMBIENTAL, 7., 2010, Maringá. Anais...Maringá: Universidade Estadual de Maringá, 2010(b).

- Caracterização dos acidentes geológicos e carta de uso recomendado do solo da região do loteamento Santa Rita, Blumenau/SC. In: SIMPOSIO BRASILEIRO DE CARTOGRAFIA GEOTECNICA E GEOAMBIENTAL, 7. 2010, Maringá. Anais...Maringá: Universidade Estadual de Maringá, 2010 (c). 